\title{
Development and Implementation of a Robot-based Freshman Engineering Course
}

\author{
Robert C. Maher, James Becker, Tia Sharpe, James Peterson, and Bradford A. Towle \\ Department of Electrical and Computer Engineering \\ Montana State University \\ Bozeman, MT 59717-3780 USA \\ rob.maher@montana.edu
}

\begin{abstract}
We describe the background and rationale for a new freshman course incorporating construction and testing of a small mobile robot. The custom robot kit is assembled in stages as the novice students learn basic electrical principles, the terminal characteristics of circuit components, and the basic practical skills necessary to build and test a printed circuit board. In this paper we explain the risks and difficulties overcome during the course development, the features and capabilities of the custom robot kits, and the assessment results for our first group of 90 students during the Fall 2004 semester. This effort is supported by an Educational Enhancement Award from the Montana Space Grant Consortium.
\end{abstract}

\section{Introduction}

University engineering programs typically provide at least one course at the freshman level to introduce new students to the field of engineering. These introductory courses are intended to teach some basic engineering principles, to stimulate creative thought and observation, and to retain students who might otherwise become discouraged while taking the traditional physics, calculus, and chemistry prerequisites. ${ }^{1,2,3}$

The Department of Electrical and Computer Engineering (ECE) at Montana State University (MSU) has developed and implemented a new laboratory experience in EE 101, our required freshman-level introductory course, as part of an ongoing course and curriculum evaluation process. Students in EE 101 now work on a custom autonomous robot kit, assembling the electronics and chassis components step-by-step with soldering irons and hand tools, while gaining an understanding of basic laboratory instruments, measurement procedures, and circuit concepts. The students learn to work both independently and with a partner to complete the assembly, measurement, and documentation steps via a set of newly developed instructional guides and laboratory experiments.

The remaining sections of this paper are organized as follows. First, a brief description of the motivation and rationale for the new robot-based course is given, including some information on the prior EE 101 course. Next, we describe the objectives and assessment plans for the new course, followed by the implementation details and laboratory outlines. Finally, we discuss our 
experience this year creating the new course and give several suggestions for other universities that might be interested in creating a similar robot-based freshman course.

\section{Rationale for the new course}

As mentioned above, at nearly all of the nation's universities freshmen engineering students take an introductory laboratory course. ${ }^{4,5,6}$ The manner in which the introductory material is presented can profoundly influence a student's enthusiasm and interest in subsequent course work and, ultimately, a successful professional career. Realizing this importance, the Montana State University ECE Department has devoted a considerable amount of time and effort refining the content of the freshman course, EE 101, and its method of presentation. Given this context, we chose to:

- Rejuvenate our EE 101 course utilizing student-constructed roving robots. The course continues to incorporate hands-on learning, teamwork, problem-solving skills, and an introduction to the analytical and design processes underlying modern engineering science;

- Actively engage promising young engineering students in the fields of electronics, robotics and embedded computer systems - areas of ever-increasing importance to this nation's goals in communications, transportation, and space exploration.

and

- Produce mechanical drawings, schematics, laboratory experiments, and supplementary materials sufficient to allow other universities to adapt the course to their own needs. Providing material suitable for pre-engineering courses at Montana's Tribal Colleges is one specific example.

We also wanted to align the new freshman course with our planned outreach programs in order to provide an active relationship between the producers - high schools and technical schoolsand the consumers - college-level math, science, and engineering programs — of motivated and well prepared college students. The benefits of these relationships include:

- Students involved with university-sponsored outreach programs are more likely to consider college a viable alternative to entering the workforce directly after high school.

- Curriculum content provided by outreach programs can influence the area of study chosen by college-bound students.

- Pre-college teachers are provided with resources and points of contact that result in improved currency of their curriculum.

\section{Objectives}

The new EE 101 has four primary objectives.

(1) Develop a compelling opportunity for students to learn circuit theory, characteristics of standard electronic components, and electrical laboratory measurement procedures.

First-year students must learn to deal with electrical circuits expressed as schematic diagrams, as mathematical equations and models, and as an assemblage of actual physical components. 
Learning these abstract concepts is easiest when treated holistically, because each viewpoint provides a distinct and useful insight for analysis of electrical systems.

(2) Capture the imagination of first-year engineering students: instill in them a feeling of accomplishment and confidence in their achievement.

Students generally learn most easily when they are actively engaged in a significant, thoughtprovoking, and hands-on project. Their observation skills are activated and their imaginations are occupied with "what if?" questions. Yet, it is also necessary for them to gain confidence in their ability to follow a sequence of steps, solve problems, identify alternatives, and successfully accomplish a difficult goal.

(3) Raise awareness of electrical and computer engineering career opportunities among potential students throughout the region.

Although EE 101 is conducted at the university level, there are good reasons to use the results to attract and recruit high school students who might not otherwise understand the nature of an electrical engineering career, or that they could pursue their interests in robotics and aerospace concepts while staying in Montana. Moreover, our increasing connections to the American Indian Tribal Colleges in Montana could allow us to reach and attract these individuals.

(4) Document the project so that the robot design and supporting educational materials can be sustained at Montana State University and disseminated to other institutions in Montana and beyond.

The effort required to implement the new EE101 course was sufficiently high that it would be difficult to start from scratch at most campuses in this geographic area of the country. By carefully documenting the robot design, the course modules, and the options for expansion, the likelihood of adoption at another university can be greatly enhanced.

Of course, the use of mobile robots in engineering education is hardly a novel idea. ${ }^{7}$ Mobile robots have been used at Carnegie-Mellon University, Penn State, Western Michigan (cf., http://homepages.wmich.edu/ miller/ECE123.html), the University of Colorado, and undoubtedly many other colleges of engineering. Also, IEEE has supported the Stiquito robot concept (http://www.computer.org/books/stiquito/ ), ${ }^{8}$ and NASA is involved with Dean Kamen's FIRST robotics competition (http://www.usfirst.org). Thus, our level of confidence was boosted by the success of such highly-qualified pioneers. ${ }^{9,10}$

\section{History: the previous EE 101}

Prior to this year the MSU ECE Department used a hands-on approach in which first-year students assembled elementary electronic circuits on a prototype board, learned to perform electrical measurements, and gained experience with the mathematical and analytical fundamentals of electrical engineering. The course objectives were simply to have the students learn several basic electrical engineering concepts, such as Kirchhoff's and Ohm's laws, and to motivate them to continue their studies. While the EE 101 class received good student evaluations and appeared to be well received, it was not all that the faculty wanted it to be. We were interested in setting a higher expectation for the class, and decided to reexamine the goals of the course and to change its format to 2 credit hours, with a separate 50 -minute lecture in addition to the 2-hour lab session. 
Concurrently, Jim Peterson (MSU ECE Department Head) challenged the ECE faculty to consider whether it might be possible to develop a small mobile robot that could become the platform for learning in EE 101 and subsequent courses. His suggestion was stimulated by the growing number of students arriving at the University interested in the nation's space exploration program and with ambitions for designing and building microcontroller-based robots: the robot platform would enable student learning and serve as a great motivator for further studies in engineering. Recent popular television programs have raised public awareness of mobile robots, and with the vehicles Spirit and Opportunity currently on the surface of Mars, the popularity of mobile robots is increasing even more.

MSU Adjunct Professor Bob Gunderson and undergraduate assistant Gary Schoep developed a prototype small mobile robot kit as a starting point for the EE 101 platform, but converting the prototype into a version ready for 100 students to build successfully each semester was clearly going to take further work. Although the Department was eager to see the revised EE 101 curriculum put in place, we were realistic in our assessment that the faculty time and effort required to develop and implement the course would significantly exceed the normal teaching load for that course. Thus, we prepared a proposal for the NASA Montana Space Grant Consortium Educational Enhancement program to fund a month of summer faculty time, purchase prototype supplies and the first set of 100 lab kits, and support part-time hourly student assistants. We were fortunate to be chosen for MSGC funding, and the EE 101 project received \$36,000 to be expended over 12 months beginning in March of 2004.

\section{Pedagogy}

Integrating mobile robotics into the EE 101 course framework required a 15-week lesson plan reflecting the project goals while recognizing the relative inexperience of the students. The course organization encompasses three viewpoints within each lab exercise:

Practical assembly steps - The students have an opportunity to use hand tools, solder stations, wireless breadboards, and similar manual tools for mechanical construction and prototype development. Some students may already be well acquainted with such things, but our experience has shown that fewer and fewer entering freshmen have tinkered with amateur radio, auto mechanics, or other hobbies that were popular among engineering students in the past. We feel that requiring hands-on activity reinforces the concepts and gives the students more selfconfidence as they learn the basic electrical principles.

Measurement and testing-Engineering requires a basic understanding of measurement methods including the operation of standard laboratory instruments, proper test procedures, and the difference between precision and accuracy. We use the mobile robot platform to introduce the multimeter and oscilloscope via measurements before, during, and after assembly. In later exercises the test equipment is used to diagnose problems and assess performance adjustments.

Mathematical models - The key ingredient separating engineering from the physical sciences is the concept of design: being able to balance scientific, technical, and economic tradeoffs in order to devise a useful and sustainable solution to a problem. Evaluating tradeoffs must involve physical principles and the abstraction of a mathematical model. Therefore, we consider it vital 
to expose the students to mathematical representations of electrical and electromechanical systems while assembling and studying the mobile robot.

\section{Implementation}

Armed with our objectives and pedagogical goals, we began to sketch the outline for the 15week course and the final details of the custom robot kit. The specific topics and skills we wanted the students to learn included:

- Resistance

- AC signals

- Capacitors

- Voltage and current (DC)

- Batteries and DC bench power supplies

- Loop and node equations

- Matlab for signal and circuit analysis

- Digital Multimeters (DMMs) - Measurements and operating principles of an oscilloscope

- Circuit assembly, breadboard and printed circuit board (soldering)

- Diodes, light-emitting diodes (LEDs), multisegment LED displays

- Ohm's Law, Kirchhoff's Voltage Law (KVL) and Kirchhoff's Current Law (KCL)

- Miscellaneous components: transistor switch, servo motor, voltage regulator, Analog-to-digital converter

- Motion sequencing with a microcontroller

Thus, we proceeded with the design of the robot kit in a way that would allow step-by-step assembly and testing as the students learned each concept. For example, in the first few labs the students create simple single-loop circuits on the breadboard, make measurements with the digital multimeter (DMM), calculate predicted voltages and currents with Ohm's Law and Kirchhoff's Laws (KVL/KCL), and consider issues of precision and accuracy for electrical measurements. Then, as they gain experience and confidence with the lab equipment, they are introduced to printed circuit board assembly, verification, and testing.

Another important consideration was the need to review circuit concepts systematically. It has been our experience that freshmen students do not gain a working knowledge of circuit analysis and measurement techniques the first time they are explained, but instead must have the opportunity to see the concepts in a variety of contexts over at least several weeks. Therefore, after introducing the students to Ohm's Law, they measure the terminal characteristics of a resistor in the lab, figure out the color code, and compare the nominal value to the resistance actually measured. The next week they see and measure a potentiometer and learn the voltage divider concept. Then in the subsequent week they solder resistors onto their robot printed circuit board and calculate series and parallel resistor combinations, and so forth.

Based on our course objectives and pedagogical goals, we came up with a list of desired features for the robot kits. We felt that it would be most effective to have each student purchase, construct, and keep his or her own individual robot. We examined several commercial educational robots, such as the LEGO Mindstorms ${ }^{\mathrm{TM}}$ system (http://www.lego.com/eng/products/next/ ) and the Parallax Boe-Bot (http://www.parallax.com/html_pages/robotics/ ), but ultimately decided that our learning goals and cost targets would be better served by developing our own custom robot design.

Although commercial small robot kits often cost \$200 or more, an informal survey of our freshmen students revealed a strong aversion to spending more than $\$ 125$ or so: the equivalent cost of a typical engineering textbook. Moreover, we wanted the students to learn about the actual circuitry and components at the electrical level, so a pre-fabricated kit was not appropriate 
for our needs. Therefore, we set a raw bill of materials (BOM) cost of $\$ 80$ to allow some overhead for parts inventory, shipping, and local stock room markup.

\section{Robot Physical description}

The custom robot design, dubbed "ECEbot," consists of a 12cm x 12cm octagonal aluminum chassis base plate with a matching octagonal printed circuit board mounted as a sandwich with aluminum bracket spacers. The space between the base plate and the printed circuit board (PCB) is used to mount the battery pack, two DC servo drive motors, and attachments for a pair of bumper switches.

The robot is controlled by a Freescale (formerly Motorola) HC12 derivative, the 9S12C32, mounted in a 32-pin self-contained module, the M68MOD912C32

(http://www.freescale.com/webapp/sps/site/prod_summary.jsp?code=M68MOD912C32 ). The microcontroller allows the behavior of the robot to be tailored to the particular topic of each lab assignment. The controller also allows the features of the system to change with time as new software and control algorithms are developed.

The microcontroller module includes an RS-232 serial driver/receiver chip, clock crystal, background debug mode port, and boot/run switch. The processor includes 32 kilobytes of flash memory (reflash over RS-232 supported) and 2 kilobytes of RAM, so it is possible to provide the students with a pre-programmed microcontroller while still allowing future code updates by downloading over the RS-232 connection from a personal computer.

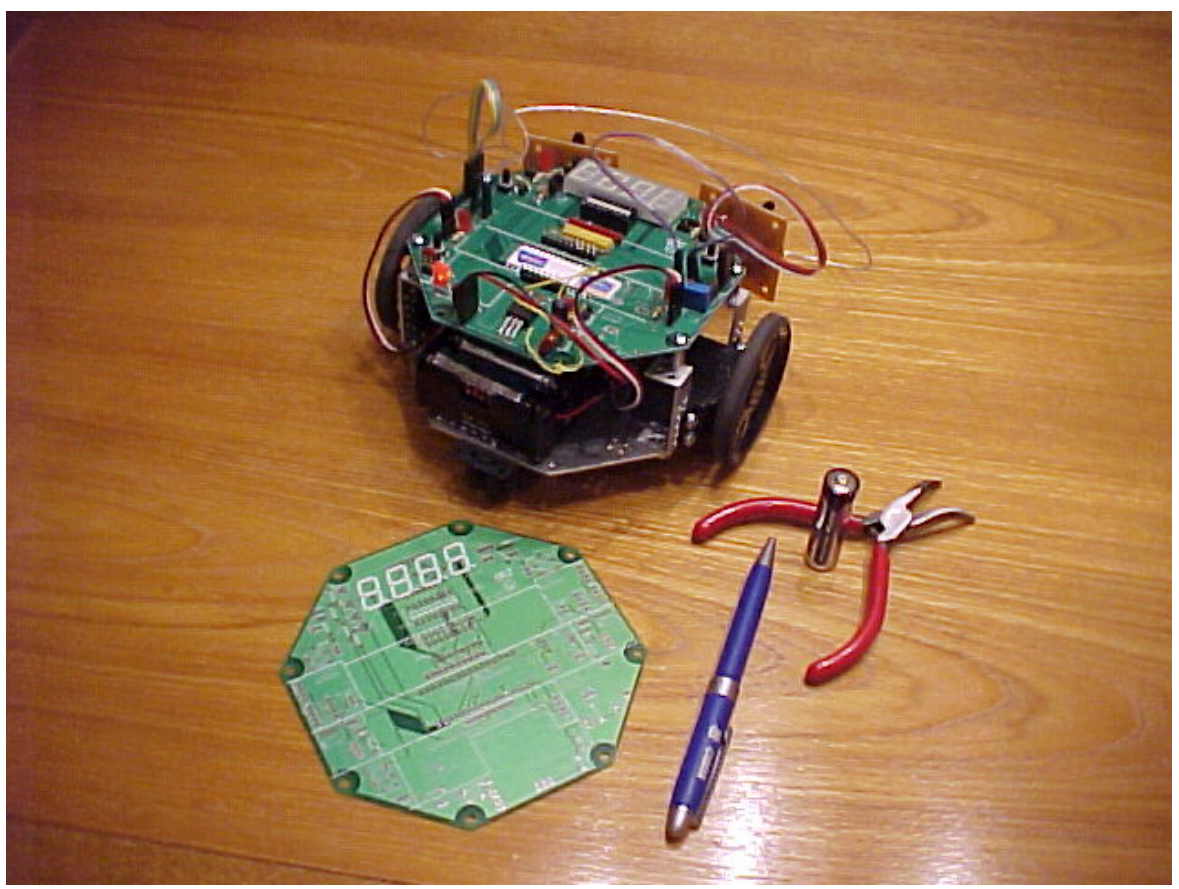

"ECEbot" viewed from behind 


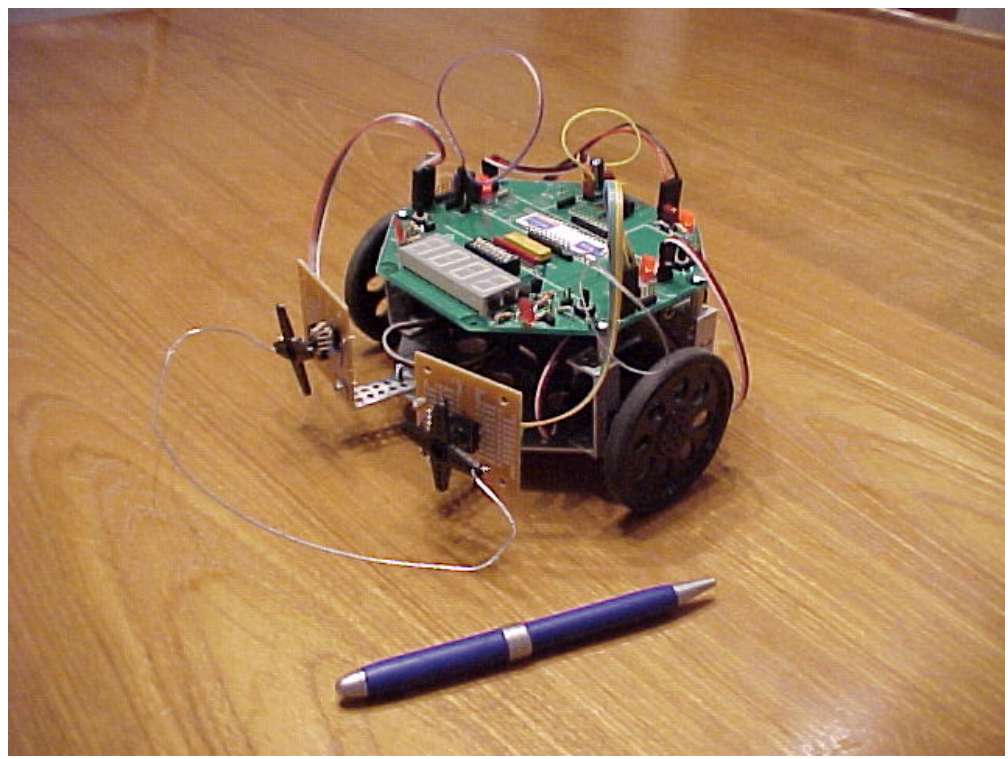

"ECEbot" viewed from the front

The printed circuit board is designed to allow various connections, modifications, and test configurations. Header pins are provided for monitoring and rerouting signals on the board, as well as injecting external signals for measurement and calibration. A block diagram of the basic PCB features, and the upper layout artwork of the PCB is shown below.

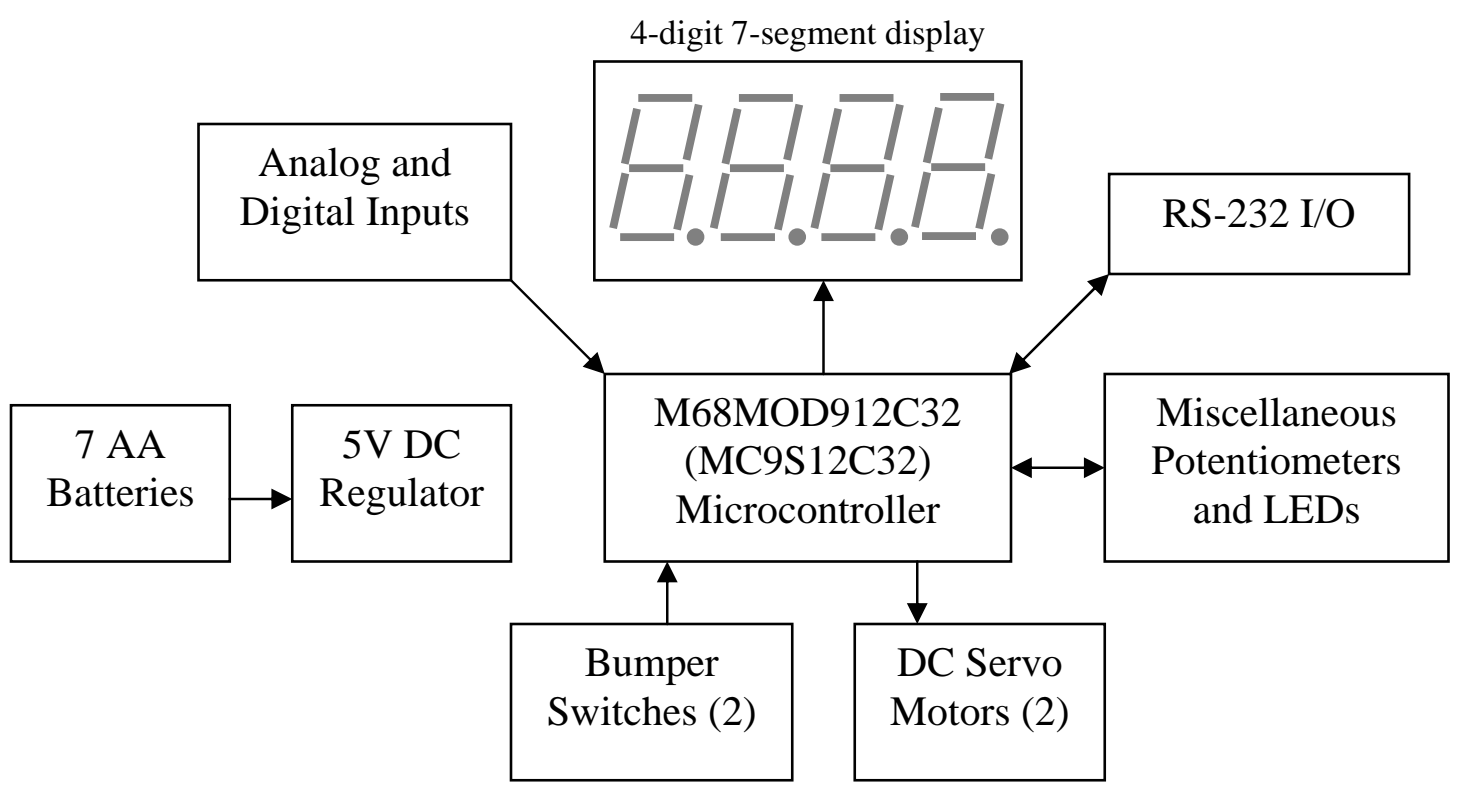




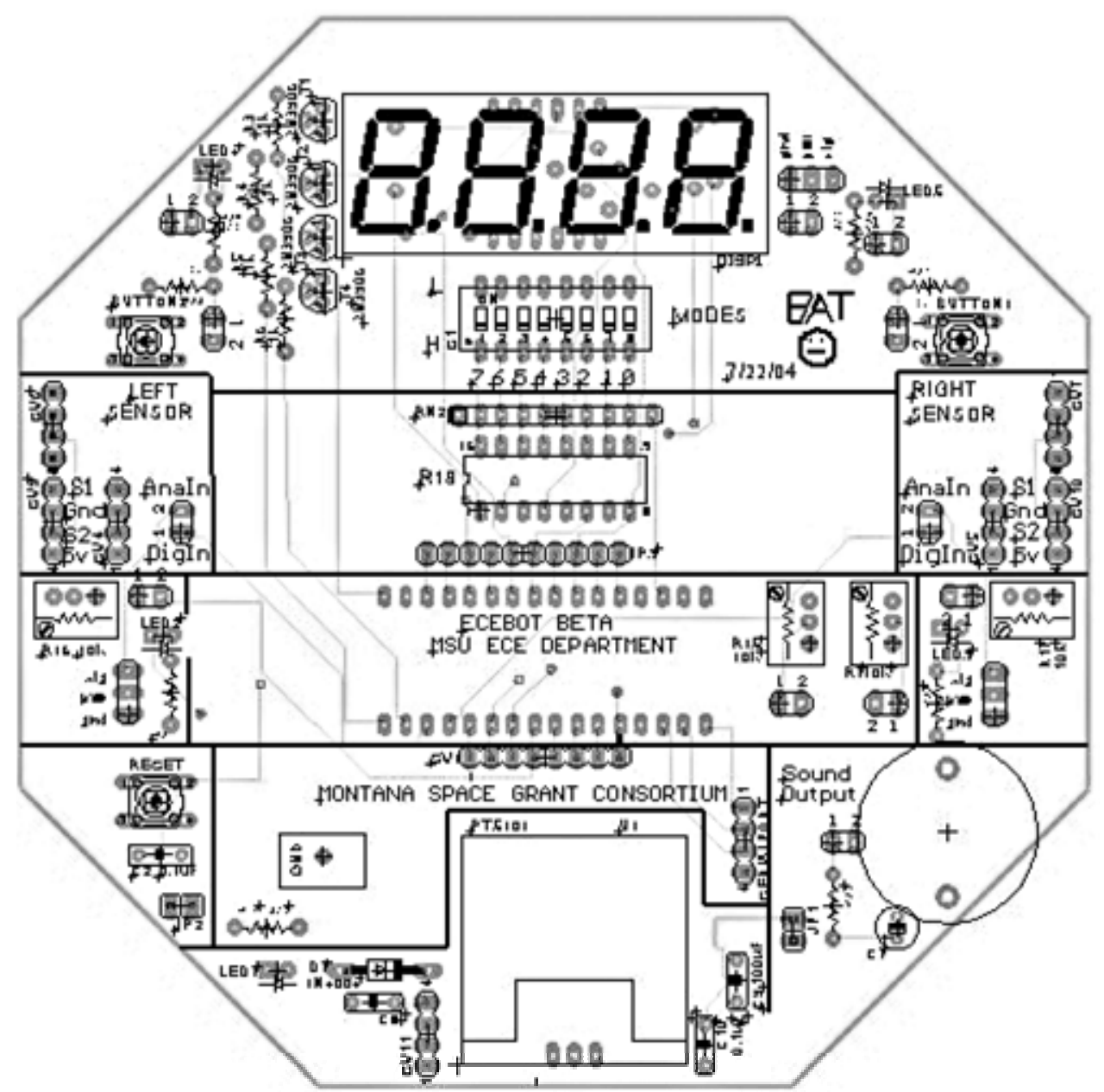

The PCB was implemented using CadSoft EAGLE (Easily Applicable Graphical Layout Editor, http://www.cadsoftusa.com/ ) schematic capture and routing software as a simple 2-layer board that could be manufactured for well under \$10 in quantity. The PCB and the default code that was pre-installed on the microcontroller was devised and implemented by our capable undergraduate assistant, Brad Towle.

The DC servo motors chosen for the robot were Futaba motors modified by Parallax for continuous free rotation in either direction according to the pulse width signal applied by the microcontroller. The rear of the robot includes a small roller-ball caster (unpowered). Thus, the controller is able to move the robot forward, backward, or rotate left or right by providing the proper pulse signals to the DC servo motors: no mechanical turning mechanisms are needed.

The microcontroller is able to read the position of 8 dual-inline package (DIP) switches that are used to specify the startup behavior of the controller after a reset. Similarly, the controller is able to monitor several analog and digital input signals that can be provided by bumper (contact) switches, optical detectors, and other possible sensor devices.

Due to the limited amount of time available in EE 101, we decided not to try to teach microcontroller programming in the course. Instead, we chose to pre-program the 
microcontroller's flash memory with a set of seven default programs covering a useful range of test conditions and simple motion behavior.

\section{Course Outline}

The 15-week course calendar ended up yielding space for a total of 11 lab experiments, an introductory week, 2 weeks reserved for tests and demonstrations, and a week off to accommodate various campus holidays. The overall lab outline and a brief summary of the individual lab experiments are as follows.

\section{Lab \#1: Batteries, Power Supplies, and Resistors}

Platform: breadboard, resistors, batteries

Topics: Resistor color code; Using DMM to measure voltage and resistance; Nominal values vs. actual measured values; Parallel and series resistor combinations; Dry cell batteries and the bench power supply. Assembly: none

\section{Lab \#2: Ohm's and Kirchhoff's Circuit Laws}

Platform: breadboard, potentiometer from parts kit

Topics: KVL and KCL; Measuring DC voltage and current; Potentiometers; Circuit board assembly methods: component placement and hand soldering.

Assembly: robot construction steps 1 and 2 (solder on socket and power system)

\section{Lab \#3: AC Signals and the Oscilloscope}

Platform: breadboards, resistors, capacitors

Topics: Using the oscilloscope: voltage vs. time graph; Comparing scope and DMM for DC voltage measurements; Function generator: various AC signal types; Capacitors; terminal characteristics and types; Making a simple RC circuit measurement (compare input and output); Intro to frequency response. Assembly: robot construction steps 3 and 4 (resistor packs, transistors, buttons, pot, headers)

\section{Lab \#4: Digital Signals}

Platform: breadboards, begin using assembled robot PCBs

Topics: Using the oscilloscope: practice and reinforcement of skills; Pulse waveform, frequency and duty cycle; LEDs: flashing; 4-digit 7-segment display.

Assembly: solder steps 5 and 6 (display resistors, display, dip switches, LEDs)

\section{Lab \#5: Robot Board Sub-System Testing}

Platform: robot

Topics: Continuity testing; Voltage regulator; Transistors as electronic switches; Pushbuttons and LEDs. Assembly: start chassis and bumper switches

\section{Lab \#6: Introduction to MATLAB}

Platform: PCs in computer lab

Topics: Learn the basic features of Matlab (entering numeric sequences, arithmetic, plotting)

Assembly: complete chassis assembly and bumpers

\section{Lab \#7: Microcontroller and Motor Testing}

Platform: completed robot

Topics: Connect bumper switches and test; Install and boot pre-programmed microcontroller; Observe signals, measure frequency and duty cycle; Arrange motor rotation and verify behavior.

Assembly: install microcontroller, finalize chassis-PCB attachment and complete the robot 


\section{Lab \#8: A/D Converter and ECEbot Bumpers}

Platform: completed robot

Topics: A/D converter; Bumper signal testing and observation; Run and verify the motion test modes; System demos for the class.

Assembly: none

\section{Lab \#9: MATLAB for EE problem solving}

Platform: PCs in computer lab

Topics: Solving simultaneous equations; Representing circuits and components; Evaluating solutions.

Assembly: none

\section{Lab \#10: Control and Motion Sequencing}

Platform: completed robot

Topics: Download direction commands to robot; Motion sequencing to navigate a small obstacle course.

Assembly: none

\section{Lab \#11: Final course navigation event}

Platform: completed robot

Topics: motion sequencing contest (determine a sequence of commands to navigate a fixed course). Assembly: none

The following is a brief excerpt from the printed circuit board assembly guide. Note that the guide is written for the EE 101 audience: most of the students have never picked up a soldering iron before.

The entire set of documents used in EE 101 for the Fall 2004 semester are available on line at the following URL:

http://www.coe.montana.edu/ee/rmaher/ee101/ecebot/

\section{Project Assessment Plan}

A significant advantage of the EE 101 project is its integration into a standard required course in our curriculum. This ensures that the existing procedures for continuous assessment, documentation, and performance improvement required by the engineering program accreditation body, ABET, will be used and fully supported by the Department and the College of Engineering. The Department's procedures for course assessment are based on evaluating specific outcomes that support the broader program objectives. Outcomes assessment includes traditional examinations, student questionnaires, student performance with oral and written communication, and peer review of course materials and grading policies. 


\section{(Excerpt from "ECEBot Assembly Guide"...)}

\section{Soldering Step 1: Attach the 32-pin Socket (Back of Board)}

First, hold the board with the front side up and oriented so that you can read the printed silk screen labels from top to bottom, like in the next figure. Now turn the board over (sideways) so that the top remains at the top, and look at the back side. The rectangular group of holes area near the middle of the board (U2 label, outlined in black in the board back figure) is the 32-pin socket that will hold the microcontroller. A socket merely holds other components and aids in removing and replacing that component if necessary.

Do not proceed until the instructor has demonstrated how to use the soldering iron and you have practiced making several solder joints using one of the scrap circuit boards in the lab.

Find the 32-pin socket in your lab kit. With the small notch toward the left, line up all 32 pins of the socket with the holes on the back of the PCB (see figure) and hold the socket flush against the board as you flip it over.

\section{2-pin Socket}

(notch to the left)

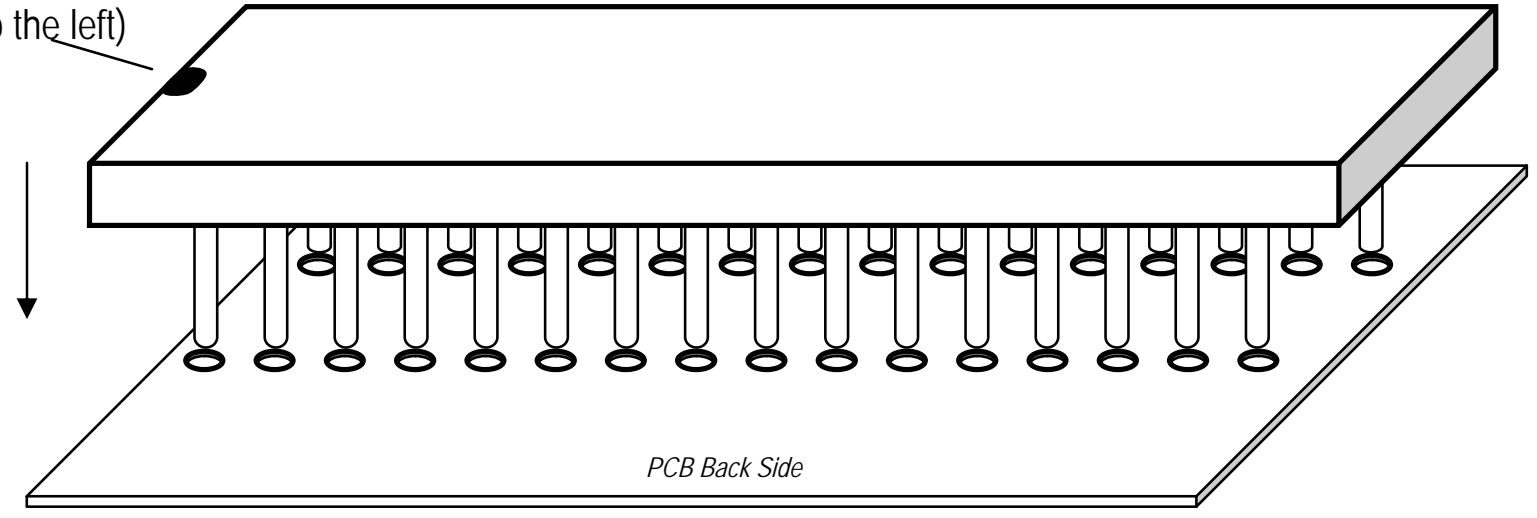

Placing the 32-pin socket onto the back of the PCB

Once flipped over, you should now see the 32 pins protruding from the holes on the front side of the board (see figure).

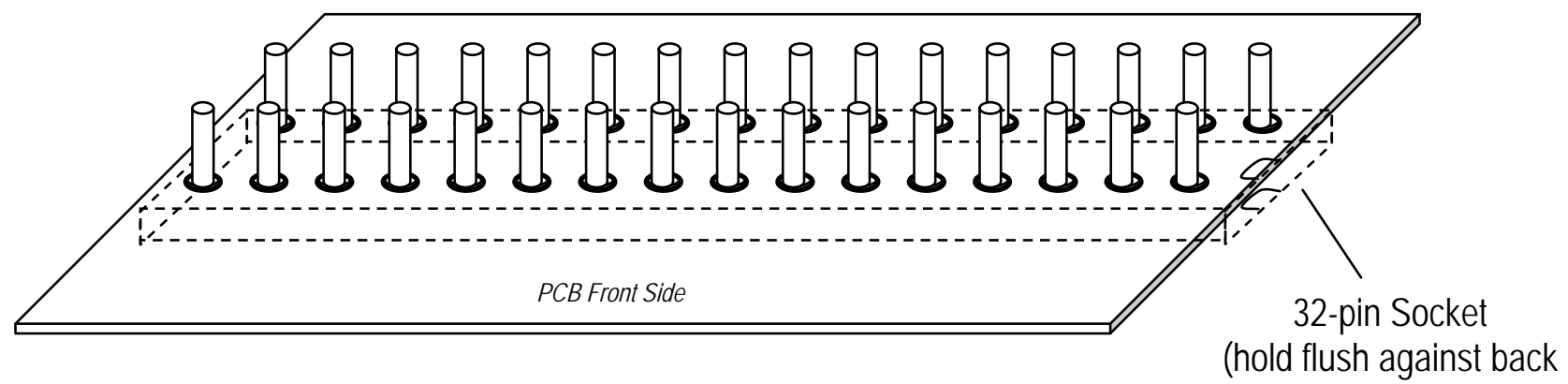

Socket pins protruding from the front of the PCB 
Hint: You may be able to hold the socket in place by resting the board face up flat on the bench top, with the socket sandwiched underneath. You might also choose to use some tape to hold the socket in place temporarily while you do the soldering.

$\rightarrow$ Carefully solder each of the 32 pins where they protrude from the front surface. Only use enough heat and solder to make a clean, shiny, and uniform joint that fills each pad but does not seep over to touch any of the adjacent pads. Have your instructor or TA look at your soldered socket and approve your technique before continuing.

\section{Soldering Step 2: The Power System Components}

In this section, the power system for the robot will be introduced. Hold the PCB with the front side up, the silk screen oriented so you can read the main labels, and locate the power section of the board in the lower left corner (see figure).

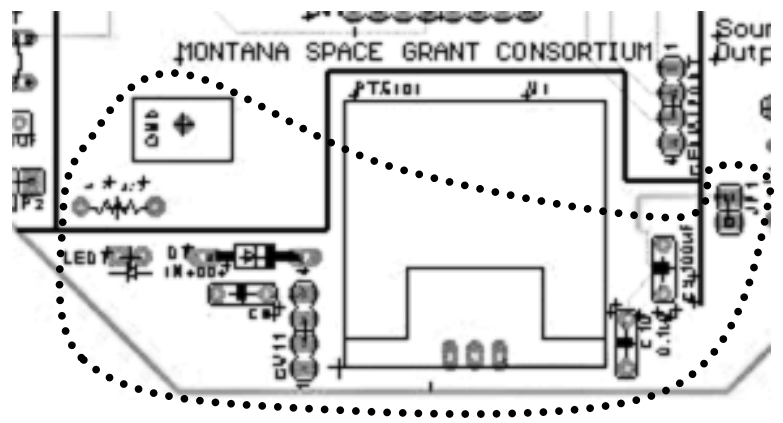

Power system section (front side, bottom left)

\section{Installing the passive components}

Carefully bend the wire leads on the $470 \Omega$ resistor and insert the leads from the front of the board through the proper pair of holes labeled R18, in the lower left corner of the board. It is always wise to double-check the component and its placement before soldering, since removing soldered parts is not easy and often results in damage to the board and to the component.

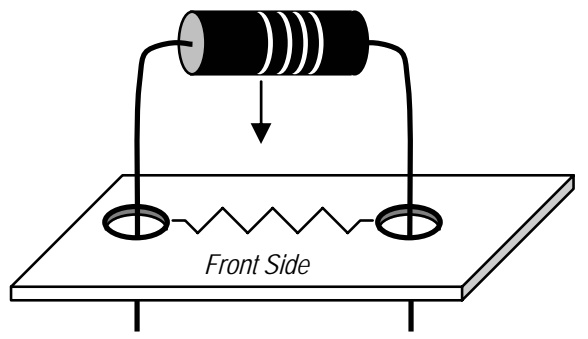

Hint: Once the component leads are through the board, bend the ends slightly on the back side of the board so that the component won't slide out of the holes when you flip the board over.

\section{(...End of Assembly Guide excerpt)}


In addition to the existing accreditation-related assessment procedures, we used two special assessment measures. First, we plan to use a special questionnaire administered in the introductory electrical circuits course (EE 206) that follows a student's participation in the revised EE 101. The special questionnaire solicits feedback on the level of preparation achieved by the student in subsequent courses, and measure the student's current level of motivation and enthusiasm. This information will be compared to students who have taken the previous nonrobot-based EE 101 course in order to draw conclusions about our progress toward the course goals. Second, we will keep a record of all students successfully completing EE 101, and establish an exit interview in the event that a former EE 101 student chooses not to continue in the ECE program. The exit interview will consist of a few brief questions regarding the role EE 101 played, if any, in the decision to leave the program. Although it may be difficult in general to reach students who are no longer enrolled, we feel this is an important aspect of our goal to encourage and motivate students toward technology-related careers. Our experience so far has been that it is relatively easy to contact students who transfer from the ECE Department to another major within the University, but students who leave MSU entirely are much more difficult to track.

\section{Preliminary Results and Evaluation}

Despite the fact that the lectures, robot kits, and lab experiments were entirely new for the Fall 2004 semester, the consensus of the 96 students enrolled has been that the course is a great success. A special end-of-course survey was prepared and assessed by Carolyn Plumb, an expert in instructional evaluation not otherwise involved with the EE 101 course. 88\% of the students reported that their interest and enthusiasm for electrical engineering was increased by the robot project, 89\% reported that they gained practical and useful knowledge in the course, and more than half of the students felt that the course had given them more confidence in their ability to succeed in engineering. A small percentage of the students reported that the course had caused them to rethink their interest in $\mathrm{EE}$, but this is not necessarily a negative outcome: helping students make a more informed decision about baccalaureate major choices early in their college career can be helpful to the student and the faculty — and often the student's parents—rather than getting several years into a degree program that the student discovers to be unappealing.

Essentially all of the students completed the robot assembly process, installed the microcontroller chip, and verified their robot's functionality. The 3 or 4 students who did not complete the assembly had dropped the course during the semester. We are following up with those students to determine what role the revised EE 101 course had in their decision to leave before the end of the semester.

In addition to the EE 101 students, we also engaged two undergraduate ECE Senior Design project teams and one undergraduate College of Engineering Senior Multidisciplinary Design team to work on developing new software and sensors for the ECEbots, as well as designing new configurations that are more easily constructed and lower in cost. It has been particularly interesting to see the reaction of the seniors in our program to the new EE 101: the most common reaction is "gee, I wish we had been able to build a robot when WE were freshmen!" 


\section{Recommendations}

Our experience with EE 101 has been very positive and rewarding. The effort that went into designing the robot kits, writing the assembly guides, devising the laboratory experiments and preparing the weekly lectures was quite high, but we are pleased to find that the ongoing effort should be sustainable for future semesters.

We have several suggestions for other electrical engineering programs that might be considering a robot-based freshman course, as summarized below.

\section{(1) Consider ways to adopt existing building blocks and components}

It is often tempting and intellectually appealing to take a clean slate approach to curriculum development. However, the amount of time and effort required to create an effective and sustainable course, particularly when lab exercises are involved, makes it much more practical to incorporate existing modules to the extent possible. For example, we chose to use a custom aluminum chassis plate and mounting brackets rather than identifying acceptable off-the-shelf items. Although the chassis components were not particularly expensive, the logistical hassle of arranging for the plate fabrication and the need to retool whenever changes are made in the future suggests that in retrospect we would have been better off choosing a readily-available option. In fact, we are now working on an alternative design that does away with the need for the chassis plate entirely by using the PCB itself as the main structural element.

\section{(2) Secure "buy-in" from faculty colleagues}

It has been our experience over the years that any newly developed course enjoys a period of the "Hawthorne Effect:" the new curriculum works well due to the noticeable effort and enthusiasm of the instructor and the willingness of the students to feel that they are contributing to the success of the course. As time goes on, however, the initial spark and interest often gives way to routine familiarity and the course effectiveness declines. This is particularly true if a less enthusiastic instructor is assigned to teach the established course. Thus, we suggest that a professor contemplating the use of hands-on robot kits should first recruit several faculty colleagues to help work on the project. In this manner it is possible to sustain a degree of excitement and continuous quality improvement from one semester to the next as several different faculty take turns teaching the course. The faculty team approach also has the obvious advantage of dividing up the workload when changes and enhancements are required.

\section{(3) Provide sufficient equipment and supervision in the lab}

We found that the students quickly became frustrated if they had to wait in line to use a soldering iron or to have an assembly question answered. It is clearly desirable, if the equipment budget allows, to have a soldering iron for each student or for pairs of students. It is also desirable to have several experienced eyes and hands available in the lab, especially during the first few weeks of kit assembly, so that the students can get immediate feedback on their assembly skills. For example, we used volunteer faculty and upperclass students to come to the open lab sessions to assist the neophyte students during the first few weeks.

Despite what we thought would be sufficient supervision, we discovered several students who had soldered the 32-pin socket for the microcontroller onto the wrong side of the PC board. This was corrected by desoldering and remounting the socket, but the potential for damage to the 
board due to the rework and the extra time required to desolder the pins made it clear that this sort of error was to be avoided. Thus, we probably cannot emphasize enough the importance of having qualified advisors in the lab at the start of the course.

\section{(4) Prepare supplementary and follow-on materials}

Among the 96 students enrolled in EE 101 the first semester there were a dozen or more who quickly expressed a keen interest in working ahead, figuring out ways to improve the performance of the robot, coming up with new sensors, and so forth. It would have been very helpful to have a set of advanced exercises or extra-credit assignments to entice these highly motivated students and take advantage of their eagerness to learn.

We also noticed that at the conclusion of the EE 101 course many of the students stated that they would like to keep working with their robots and learning on their own. Thus, we recommend that any similar hands-on course be designed to include a variety of optional add-on exercises and open-ended experiments that can be made available to interested students.

Another important issue for us has been the wide range of math experience among the incoming EE 101 students. Some are in college algebra, others are taking first-semester calculus, while still others have been granted advanced placement in a second or third semester calc course. This requires the level of mathematical sophistication to be adjusted among the students so that some reasonable pedagogical balance is achieved. Providing supplementary lecture notes and advanced "challenge" problems is one way to try to achieve such a balance.

(5) Involve undergraduate students in the development process

We found it very helpful to have upper-division undergraduate students involved during the course development process for EE 101. The students provided interesting insights, both formal and informal, that helped guide our choice of experiments and how much time to allocate to the various steps. Furthermore, the upper-division students gained some insights of their own into how much they had learned since they were freshmen themselves: it is helpful to remember what it was like to learn the basic electrical circuit principles for the first time.

\section{Conclusion}

In the coming semesters we will refine several of the experiments and continue to improve the quality of the instructional materials for EE 101 . We will also be validating the use of a costreduced version of the robot $(\sim 60 \mathrm{BOM})$ in order to make the course even less of a burden on the students' wallets.

The success of EE 101 also provides us with the opportunity to make use of the robots in subsequent courses. EE 101 is a required class, so after another semester it is possible for us to assume that essentially all of our students will have a robot available for homework assignments, lab projects, and other hands-on experiences.

As mentioned in the introduction, we are also interested in using the ECEbots for outreach to pre-college programs in Montana, and to disseminate the kit designs and lab experiments to other interested engineering programs for possible adoption. We would welcome contact from any of our colleagues around the country. 


\section{Bibliography}

1. Tobias, S. (1990), “They're Not Dumb, They're Different: Stalking the Second Tier,” Tucson: Research Corporation.

2. Besterfield-Sacre, M. E., and C. J. Atman (1994), "Survey Design Methodology: Measuring Freshman Attitudes about Engineering,” Proceedings, 1994 ASEE Annual Conference, ASEE.

3. Besterfield-Sacre, M. E., C. J. Atman, and L. J. Shuman (1997), "Characteristics of Freshman Engineering Students: Models for Determining Student Attrition in Engineering,” Engineering Education, vol. 86, no. 2, pp. 139-150.

4. Felder, R.M. and L.K. Silverman (1988), "Learning and Teaching Styles in Engineering Education,” Engineering Education, vol. 78, no. 7, pp. 674-681.

5. Ercalano, V. (1995), “From Sleep 101 to Success 101,” ASEE Prism, September 1995, pp. 24-29.

6. Ercalano, V. (1996), “Designing Freshman,” ASEE Prism, April 1996, pp. 20-25.

7. M. Z. Atashbar, D. A. Miller, F. Severance, R. Tanner, and M. Suchowski (2002), "Bridging the freshman engineering gap by building mobile robots,” Proceedings, 2002 ASEE Annual Conference, ASEE.

8. J. M. Conrad and J. Mills (1999), Stiquito ${ }^{T M}$ for beginners: An introduction to robotics, IEEE Computer Society, Los Alamitos, California (distributed by John Wiley \& Sons).

9. F. L. Severance, M. Suchowski, and D. A. Miller (2003), "Benefits of a hands-on introduction to electrical and computer engineering,” Proceedings, 2003 ASEE Annual Conference, ASEE.

10. J. Schmidt, C. Yang, O. Wilson, and G. Zhang (1999), "Assessment of the teaching-learning effectiveness of a freshman design course," Proceedings, $29^{\text {th }}$ ASEE/IEEE Frontiers in Education Conference.

\section{Biographical Sketches}

\section{ROBERT C. MAHER}

Dr. Maher is an associate professor of Electrical and Computer Engineering with Montana State UniversityBozeman. His research and teaching interests include digital signal processing, audio engineering, and embedded systems. He received his Ph.D. in Electrical Engineering from the University of Illinois-Urbana.

\section{JAMES BECKER}

Dr. Becker is an assistant professor of Electrical and Computer Engineering with Montana State UniversityBozeman. He is a 2004 NSF CAREER award recipient with research expertise in microwave devices and circuits. He received his Ph.D. in Electrical Engineering from the University of Michigan.

\section{TIA SHARPE}

Tia Sharpe is an Adjunct Instructor with the Montana State University Electrical and Computer Engineering Department. She teaches introductory circuit analysis and laboratory courses, including the new freshman EE 101 course described in this paper. Ms. Sharpe holds an M.S. degree in electrical engineering from Montana State University.

\section{JAMES PETERSON}

Dr. Jim Peterson is Professor and Head of the Department of Electrical Engineering with Montana State UniversityBozeman. Dr. Peterson was previously a professor with the University of Idaho, and holds a Ph.D. from Iowa State University.

\section{BRADFORD A. TOWLE}

Mr. Towle is a senior in the Computer Engineering program at Montana State University-Bozeman. He expects to receive his BS degree in May 2005. He worked full time as the student assistant for the EE 101 project during the summer of 2004. Mr. Towle is also the 2004-2005 MSU IEEE student branch chairman. 